\title{
Morphology of Sacrum and its Variations
}

\author{
${ }^{1}$ Dr.A.K.Manicka Vasuki, ${ }^{2}$ Dr.M.Nirmaladevi, ${ }^{3}$ Mrs.Deborah Joy Hebzibah, \\ ${ }^{4}$ Prof.M.Jamuna, ${ }^{5}$ Dr.K.Kalyana Sundaram, ${ }^{6}$ Dr.V.Vimala, \\ 1,3Assistant Professors, Department of Anatomy, PSG Institute Of Medical Sciences And Research, \\ Coimbatore - 641004. \\ ${ }^{2}$ Associate Professor, Department of Anatomy, PSG Institute Of Medical Sciences And Research, \\ Coimbatore - 641004 \\ ${ }^{4}$ Prof. \& Hod, Department of Anatomy, PSG Institute Of Medical Sciences And Research, \\ Coimbatore - 641004 \\ ${ }^{5}$ Associate Professor, Department of Anaesthesiology, Coimbatore Medical College, Coimbatore. \\ ${ }^{6}$ Assistant Professor, Department of Anatomy, Coimbatore Medical College, Coimbatore.
}

\begin{abstract}
Sacrum is formed by the fusion of five Sacral vertebrae and forms the lower part of Vertebral column. The opening present at the lower end of Sacral canal is known as Sacral hiatus. Anatomical variations, Morphology and Morphometry of Sacral hiatus are important clinically as well as surgically ${ }^{l}$. This study was carried out on 75 dry human sacra of unknown sex to know different features of Sacrum, anatomical variations of sacrum and to study the variations of sacral hiatus. Anatomical variations - failure of formation of superior articular process and lamina of left first sacral vertebra, incomplete development and fusion of second sacral vertebra, multiple foramens on either side of spinous process above the sacral hiatus, multiple foramens in the dorsal surface of base of the sacrum behind the auricular surface, incomplete median crest, bilateral five pelvic and dorsal foramens were identified. Various shapes of sacral hiatus were observed which included inverted u, inverted $v$, irregular, dumbbell and bifid'. The apex of sacral hiatus was commonly found at the level of fourth sacral vertebra. The mean length of sacral hiatus was measured. The mean anteroposterior diameter of sacral canal and narrowing of sacral canal at the apex of sacral hiatus was measured ${ }^{1 \& 2}$.

The knowledge of anatomical variations of Sacrum and variations of Sacral hiatus are clinically important for Caudal epidural block in Pediatric, Obsteric, Orthopedic, Urologic and Surgical practice.

The reliability and success of Caudal epidural block depends upon Knowledge of Variations of Sacrum and Variations of Sacral hiatus.
\end{abstract}

Keywords: Sacrum, lamina, variation, sacral hiatus, caudal epidural block

\section{Introduction}

Sacrum is a large, triangular bone formed by fusion of five vertebrae present between the two hip (innominate) bones. It presents concave anterior or pelvic surface and convex posterior surface. The broad base is directed above and the apex is at the lower end. The base is divided into central part consisting of body of first sacral vertebra and lateral mass or ala on either side. By its base the sacrum articulates with the fifth lumbar vertebra and by its apex it articulates with the coccyx. The base presents the upper opening of sacral canal. The superolateral margin of the body of first sacral vertebra projects forwards as the sacral promontory, which is useful in measuring the diameters of the pelvis.

The triangular sacral canal is formed by sacral vertebral foramina. The opening present at the caudal end of sacral canal is known as Sacral hiatus. The lamina and spinous process of the fifth and /or fourth sacral vertebrae fail to meet in the midline creating a deficiency known as the hiatus in the posterior wall of the sacral $\mathrm{canal}^{3}$. It is located inferior to the fourth or third fused sacral spines or lower end of median sacral crest. The remnants elongate downwards on both sides of sacral hiatus. These two bony processes are called the sacral cornua and define important landmarks during caudal epidural block (CEB). Sacral hiatus is identified by palpation of sacral cornua. Sacral cornua are felt at the upper end of natal cleft $5 \mathrm{~cm}$ above the tip of coccyx. Structures emerge from sacral hiatus are the filum terminale, fifth sacral nerves and coccygeal nerves. The hiatus provides access to the extradural space in the sacral canal.

Sacral hiatus is covered posteriorly by skin, a subcutaneous fatty tissue and the sacrococcygeal membrane when the needle has passed through the sacrococcygeal ligament, the hiatus communicates with the epidural space. The dural sac ends at the level of second piece of sacrum. Sacral canal below this level contains extradural fat, vertebral venous plexus, lower sacral nerve roots and the filum terminale. Sacral hiatus has been utilized for administration of epidural anaesthesia in obstetrics as well as in Orthopedic practice for Transpedicular and lateral mass screw placement. 
The anterior surface of Sacrum bears four anterior sacral foramina which give passage to ventral rami of upper four sacral spinal nerves and lateral sacral arteries ${ }^{4}$. The dorsal surface of sacrum bears four posterior sacral foramina which give passage to posterior rami of the upper four sacral spinal nerves.

The upper surface of the lateral mass of Sacrum is termed the Ala of Sacrum ${ }^{4}$.

Sacral canal contains the cauda equina, duramater and arachnoid mater ${ }^{5 \& 7}$. At the lower margin of second sacral vertebrae, the subarachnoid and subdural spaces terminate. The fifth sacral roots, coccygeal roots and filum terminale pierce the blind end of the dural tube. Beyond the dural tube, there is roomy extradural space in the sacral canal (capacity is $25-30 \mathrm{ml}$ ).

Reliability and success of Caudal epidural block depends on anatomical variations of sacral hiatus as observed by many authors.Caudal epidural block has been widely used for treatment of chronic back pain ${ }^{6}$. Sacral hiatus functions as a landmark when caudal anaesthesia is administered in Urology, Proctology,General surgery and Obsterics and Gynaecology practice. The present study was undertaken to find out the different features of Sacrum, variations of Sacrum and also variations of sacral hiatus which will be useful for Caudal anaesthesia.

\section{Materials And Methods}

The materials for the present study consists of Seventy five dry adult Sacra of unknown sex obtained from Anatomy department, PSG IMS \& R,Coimbatore. The measurements were taken with the help of Vernier caliper on the intact parts of normal bone. Anatomical variations of Sacrum was observed. Each sacrum was studied for different features with regards to:

\section{A.Observations :}

1.Sacral composition

2.Shape of Sacral hiatus

3.Level of apex of hiatus

4.Level of base of hiatus

5.Level of maximum curvature of sacrum at S3,S4 \&S5 vertebrae

\section{B. Measurements :}

1.Length of sacral hiatus from apex to midpoint of base

2. Anteroposterior diameter at the sacral hiatus

3. Base of sacral hiatus / intercornual distance

4. Median distance between the level of lower margin of S2 foramen and apex of sacral hiatus

5. Distance between midpoint of base of sacral hiatus to $2^{\text {nd }}$ sacral foramen

6. Transverse distance between right and left lateral sacral crest at the level of first sacral foramen

7. Distance between right superolateral crest and between the apex

8. Distance between left superolateral crest and between the apex

9. Angle between the base and left side of the triangle

10. Angle between the base and right side of the triangle

\section{Results:}

Study on the variation in anatomical features of sacral hiatus and the dorsal wall of the sacral canal is related with regards to its clinical application in Caudal epidural block in perineal surgery and painless delivery.

Sacral approach to epidural space produces reliable and effective block of sacral nerves. Epidural injection of Corticosteroids and local anaesthetic agents were widely used for symptomatic relief in low back disorder. Bony irregularities, different shapes of hiatus and defects in the dorsal wall of sacral canal have to be considered before undertaking Caudal epidural block.

1. Sacral composition was found to be higher in 42 Sacra among 75 dry Sacra which was similar to the previous studies. Fifth lumbar sacralisation and Coccygeal ankylosis with Sacrum was also observed.

Table 1: Sacral composition $(\mathrm{n}=75)$

\begin{tabular}{|l|l|l|l|}
\hline SERIAL NUMBER & SACRAL COMPOSITION & NUMBER & PERCENTAGE \\
\hline 1. & 5 segments & 42 & $56 \%$ \\
\hline 2. & 4 segments & 12 & $16 \%$ \\
\hline 3. & Fifth lumbar sacralisation & 11 & $15 \%$ \\
\hline 4. & Coccygeal fusion & 10 & $13 \%$ \\
\hline & 75 & $100 \%$ \\
\hline
\end{tabular}


2. Shape of Sacral hiatus - Inverted U shape was about 27 Sacra, inverted V shape was about 15 Sacra, Dumb bell shape was about 16 Sacra, Irregular shape was about 13 sacra and Bifid shape was about 3 Sacra and absence of hiatus with deficient doral wall in one Sacrum.

Table 2: Shape of Sacral hiatus $(n=75)$

\begin{tabular}{|l|l|l|l|}
\hline SERIAL NUMBER & $\begin{array}{l}\text { SHAPE OF SACRAL } \\
\text { HIATUS }\end{array}$ & NUMBER & PERCENTAGE \\
\hline 1. & Inverted 'U'shaped & 27 & 36 \\
\hline 2. & Inverted 'V' shaped & 15 & 20 \\
\hline 3. & Irregular & 55 & 33 \\
\hline 4. & Dumbbell & 16 & 23 \\
\hline 5. & Bifid & 3 & 3 \\
\hline 6. & Deficient dorsal wall & 1 & 1 \\
\hline & & & 100 \\
\hline
\end{tabular}

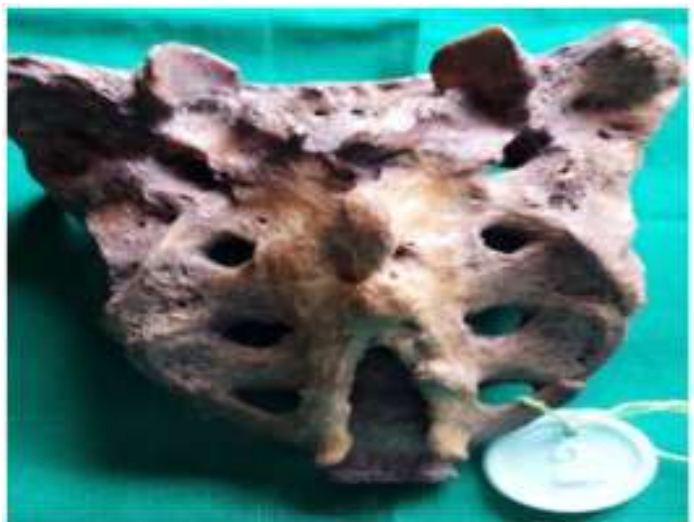

Fig.1:Inverted ' $V$ ' shaped sacral hiatus

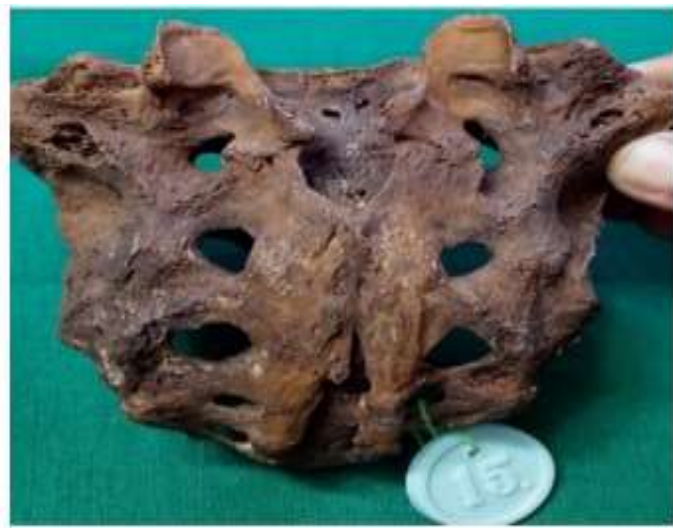

Fig.3:Dumbbell shaped sacral hiatus

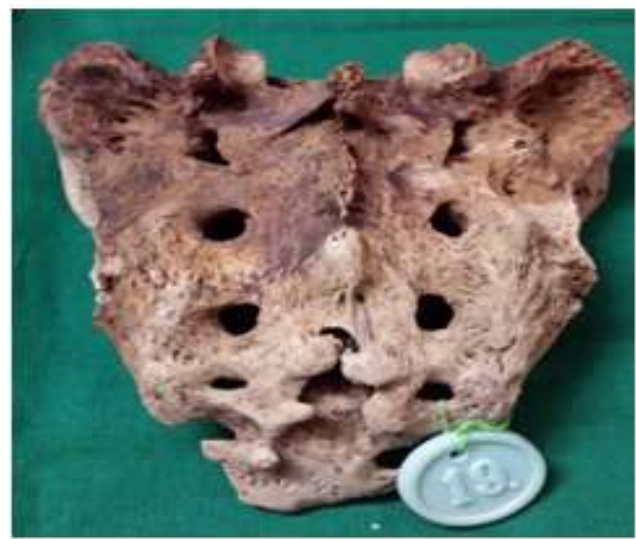

Fig.5 Bifid Sacral hiatus

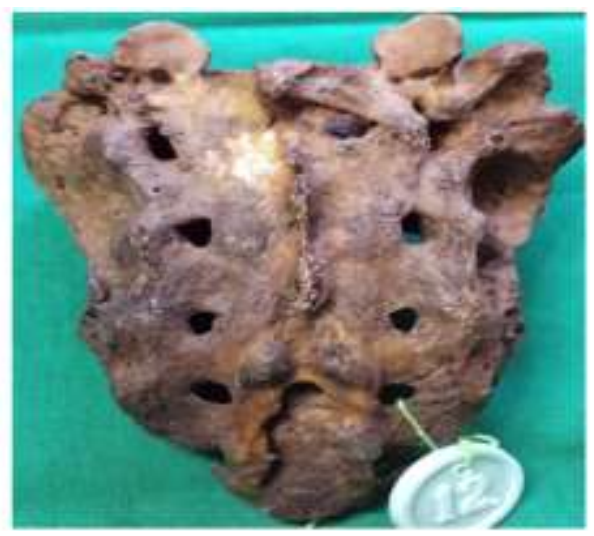

Fig.2: Inverted 'U' shaped sacral hiatus

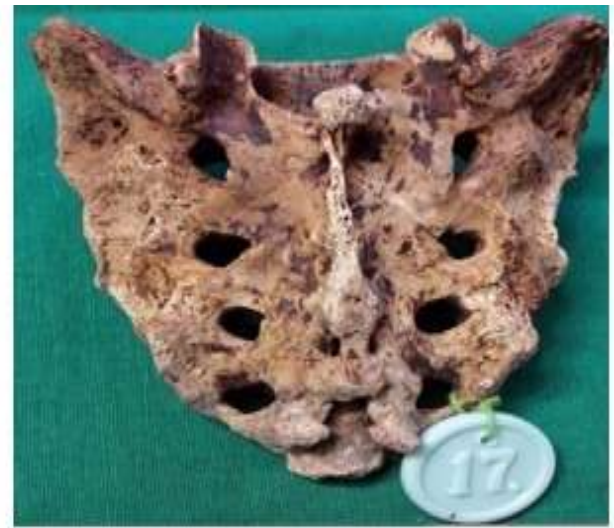

Fig.4: Irregular sacral hiatus

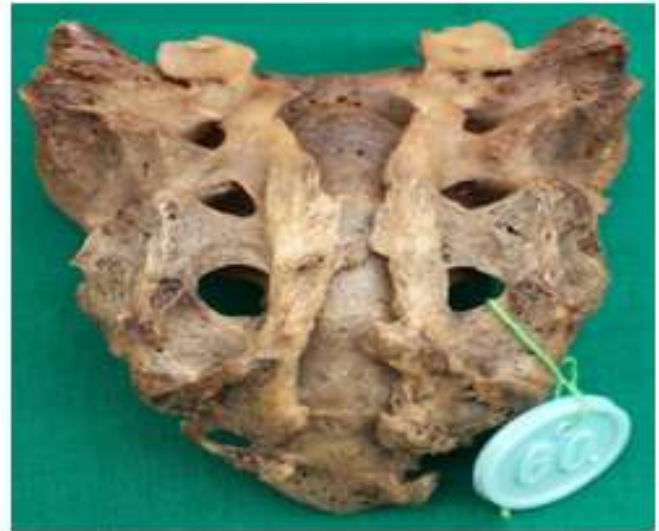

Fig.6 Complete dorsal wall agenesis 
3. Level of Apex of Sacral hiatus was seen in S3,S4 and S5 foramina and was found to be $4^{\text {th }}$ Sacral vertebra in 36 dry human Sacra. High apex is associated with high chances of dural puncture and the lower apex needs longer needle.

Table 3: Location of Apex of Sacral hiatus $(n o=75)$

\begin{tabular}{|l|l|l|l|}
\hline SERIAL NUMBER & LOCATION OF APEX & NUMBER & PERCENTAGE \\
\hline 1. & $4^{\text {th }}$ Sacral vertebrae & 36 & 48 \\
\hline 2. & $3^{\text {rd }}$ Sacral vertebrae & 32 & 43 \\
\hline 3. & $5^{\text {th }}$ Sacral vertebrae & 4 & 5 \\
\hline 4. & $2^{\text {nd }}$ Sacral vertebrae & 2 & 3 \\
\hline 5. & $\begin{array}{l}\text { Deficient dorsal wall without } \\
\text { apex }\end{array}$ & 1 & 1 \\
\hline & Total & 75 & 100 \\
\hline
\end{tabular}

4. .Location of Base was observed at S4,S5 and Coccyx and was found to be more in S5 in 48 dry Sacra. The lowest location of base at Coccyx $20 \%$ in the present study. However base when present at Coccyx was little narrower than at the sacral level.

Table 4: Location of Base $(n=75)$

\begin{tabular}{|l|l|l|l|}
\hline SERIAL NUMBER & LOCATION OF BASE & NUMBER & PERCENTAGE \\
\hline 1. & Coccyx & 15 & 20 \\
\hline 2. & $5^{\text {th }}$ Sacral vertebrae & 48 & 64 \\
\hline 3. & $4^{\text {th }}$ Sacral vertebrae & 12 & 16 \\
\hline & Total & 75 & 100 \\
\hline
\end{tabular}

5. Maximum curvature of Sacrum was observed at S3,S4 and S5 levels and was found to be S3 in 47 dry Sacra.

Table 5: Maximum curvature of Sacrum $(n=75)$

\begin{tabular}{|l|l|l|l|}
\hline SERIAL NUMBER & $\begin{array}{l}\text { MAXIMUM CURVATURE } \\
\text { OF SACRUM }\end{array}$ & NUMBER & PERCENTAGE \\
\hline 1. & S3 & 47 & 62 \\
\hline 2. & S4 & 22 & 29 \\
\hline 3. & S5 & 6 & 8 \\
\hline & Total & 75 & 100 \\
\hline
\end{tabular}

\section{Measurements}

1. Length of Sacral hiatus from apex to midpoint of base - maximum length was found to be $11-20 \mathrm{~mm}$ in 32 dry sacra. Increase in length of the hiatus is influenced by the defect of nonunion of $2^{\text {nd }}$ and $3^{\text {rd }}$ pair of sacral lamina and also by coccygeal fusion.

Table 6: Length of Sacral hiatus from apex to base

\begin{tabular}{|l|l|l|l|}
\hline SERIAL NUMBER & LENGTH IN MILLIMETRE & NUMBER & PERCENTAGE \\
\hline 1. & $0-10$ & 6 & 8 \\
\hline 2. & $11-20$ & 32 & 42 \\
\hline 3. & $21-30$ & 25 & 33 \\
\hline 4. & $31-40$ & 5 & 6 \\
\hline 5. & $41-50$ & 5 & 6 \\
\hline 6. & $>51$ & 3 & 4 \\
\hline 7. & Deficient dorsal wall & 1 & 1 \\
\hline & Total & 75 & 100 \\
\hline
\end{tabular}

2. AP diameter at the sacral hiatus was found to be $0-3 \mathrm{~mm}$. in 35 dry sacra. APdiameter of $<3 \mathrm{~mm}$ indicates that there would be difficulty in inserting the needle.

Table 7: Anteroposterior diameter of Sacral canal at the level of apex $(n=75)$

\begin{tabular}{|l|l|l|l|}
\hline SERIAL NUMBER & $\begin{array}{l}\text { ANTEROPOSTERIOR IN } \\
\text { DIAMETER } \\
\text { MILLIMETRE }\end{array}$ & NUMBER & PERCENTAGE \\
\hline 1. & $0-3$ & 35 & 47 \\
\hline 2. & $4-6$ & 31 & 42 \\
\hline 3. & $7-9$ & 7 & 9 \\
\hline 4. & $>9$ & 1 & 1 \\
\hline 5. & Deficient dorsal wall & 1 & 1 \\
\hline & Total & 75 & 100 \\
\hline
\end{tabular}


3. Base (Transverse diameter) was found to be $11-15 \mathrm{~mm}$ in 36 dry sacra. $<10 \mathrm{~mm}$ Base is sufficient to insert the needle.

Table 8: Transverse diameter (Width) at the level of cornua $(\mathrm{n}=75)$

\begin{tabular}{|l|l|l|l|}
\hline SERIAL NUMBER & $\begin{array}{l}\text { TRANSVERSE DIAMETER } \\
\text { IN MILLIMETRE }\end{array}$ & NUMBER & PERCENTAGE \\
\hline 1. & $0-5$ & 0 & 0 \\
\hline 2. & $6-10$ & 7 & 9 \\
\hline 3. & $11-15$ & 36 & 48 \\
\hline 4. & $>15$ & 32 & 43 \\
\hline & Total & 75 & 100 \\
\hline
\end{tabular}

4. Median distance between the level of lower margin of $\mathrm{S} 2$ and apex of sacral hiatus was $21-30 \mathrm{~mm}$ in 25 Sacra. Dural sac terminates at S2 level. Hence distance between apex of hiatus and S2 level decides the length of the needle that can be safely introduced into the canal.

Table 9: Median distance between the level of lower margin of S2 and apex of Sacral hiatus

\begin{tabular}{|l|l|l|l|}
\hline SERIAL NUMBER & $\begin{array}{l}\text { MEDIAN DISTANCE IN } \\
\text { MILLIMETRE }\end{array}$ & NUMBER & PERCENTAGE \\
\hline 1. & 10 & 6 & 8 \\
\hline 2. & $11-20$ & 17 & 23 \\
\hline 3. & $21-30$ & 25 & 33 \\
\hline 4. & $31-40$ & 20 & 27 \\
\hline 5. & $>40$ & 6 & 8 \\
\hline 6. & Deficient dorsal wall & 1 & 1 \\
\hline & Total & 75 & 100 \\
\hline
\end{tabular}

5. Distance between midpoint of Base to $\mathrm{S} 2$ foramen was found to be $>40 \mathrm{~mm}$ in 52 Sacra and that accounts for $69 \%$. The needle should be advanced only a few $\mathrm{mm}$ after penetrating the Sacrococcygeal membrane in adults to reduce the risk of dural puncture.

Table 10: Distance between midpoint of base to $S 2$ foramen

\begin{tabular}{|l|l|l|l|}
\hline SERIAL NUMBER & $\begin{array}{l}\text { DISTANCE IN } \\
\text { MILLIMETRE }\end{array}$ & NUMBER & PERCENTAGE \\
\hline 1. & $<10$ & 0 & 0 \\
\hline 2. & $11-20$ & 2 & 2 \\
\hline 3. & $21-30$ & 3 & 4 \\
\hline 4. & $31-40$ & 17 & 23 \\
\hline 5. & $>40$ & 52 & 69 \\
\hline 6. & Defient dorsal wall & 1 & 1 \\
\hline & Total & 75 & 100 \\
\hline
\end{tabular}

6. Distance between right superolateral sacral crest and left superolateral sacral crest was found to be $51-60$ $\mathrm{mm}$ in 40 dry sacra and that accounts for $53 \%$.

Table 11: Distance between right superolateral Sacral crest (SLSC) and left Superolateral Sacral crest

(SLSC)

\begin{tabular}{|l|l|l|l|}
\hline SERIAL NUMBER & $\begin{array}{l}\text { DISTANCE IN } \\
\text { MILLIMETRE }\end{array}$ & NUMBER & PERCENTAGE \\
\hline 1. & $<40$ & 0 & 0 \\
\hline 2. & $41-50$ & 3 & 4 \\
\hline 3. & $51-60$ & 40 & 53 \\
\hline 4. & $61-70$ & 30 & 40 \\
\hline 5. & $71-80$ & 2 & 2 \\
\hline & Total & 75 & 100 \\
\hline
\end{tabular}

7. Distance between right superolateral sacral crest and apex was found to be $51-60 \mathrm{mmin} 32$ dry sacra and that accounts for $43 \%$

Table 12: Distance between right superolateral Sacral crest and apex

\begin{tabular}{|l|l|l|l|}
\hline SERIAL NUMBER & $\begin{array}{l}\text { DISTANCE IN } \\
\text { MILLIMETRE }\end{array}$ & NUMBER & PERCENTAGE \\
\hline 1. & $<40$ & 7 & 9 \\
\hline 2. & $41-50$ & 18 & 24 \\
\hline 3. & $51-60$ & 32 & 43 \\
\hline 4. & $61-70$ & 12 & 16 \\
\hline 5. & $71-80$ & 3 & 4 \\
\hline 6. & $>80$ & 3 & 4 \\
\hline & Total & 75 & 100 \\
\hline
\end{tabular}


8. Distance between left superolateral sacral crest and apex was found to be $51-60 \mathrm{~mm}$ in 29 dry sacra and that accounts for $29 \%$

Table 13: Distance between left superolateral Sacral crest and apex

\begin{tabular}{|l|l|l|l|}
\hline SERIAL NUMBER & $\begin{array}{l}\text { DISTANCE IN } \\
\text { MILLIMETRE }\end{array}$ & NUMBER & PERCENTAGE \\
\hline 1. & $<40$ & 6 & 8 \\
\hline 2. & $41-50$ & 15 & 20 \\
\hline 3. & $51-60$ & 29 & 39 \\
\hline 4. & $61-70$ & 19 & 25 \\
\hline 5. & $71-80$ & 4 & 5 \\
\hline 6. & $>80$ & 2 & 3 \\
\hline & Total & 75 & 100 \\
\hline
\end{tabular}

9. Angle between the base and left side of the triangle and angle between the base and right side of the triangle was found to be equal. The distance from right and left superolateral crest to sacral hiatus apex is almost equal. The angles formed on the right and left sides are almost same indicating equilateral triangle. This suggested that this is an important landmark to detect sacral hiatus for Caudal Epidural Block.

Table - 14 : Measurements Of Sacrum :

\begin{tabular}{|l|l|l|}
\hline SERIAL NUMBER & PARAMETERS & MEAN \pm STD.DEVIATION \\
\hline 1. & Length of Sacral hiatus & $28.1 \pm 8.2(8-54)$ \\
\hline 2. & $\begin{array}{l}\text { Anteroposterior diameter of Sacral } \\
\text { hiatus }\end{array}$ & $5.3 \pm 1.28(2-10)$ \\
\hline 3. & Base of Sacral hiatus & $13.2 \pm 3.67(8-20)$ \\
\hline 4. & S2 to apex of Sacral hiatus & $34.6 \pm 1.21(6-52)$ \\
\hline 5. & S2 to base of Sacral hiatus & $51.2 \pm 7.83(15-58)$ \\
\hline
\end{tabular}

\section{D.Anatomical variations :}

1. Failure of formation of right first sacral lamina and superior articular process with abnormal bony growth near the first dorsal foramina.(Fig.7)

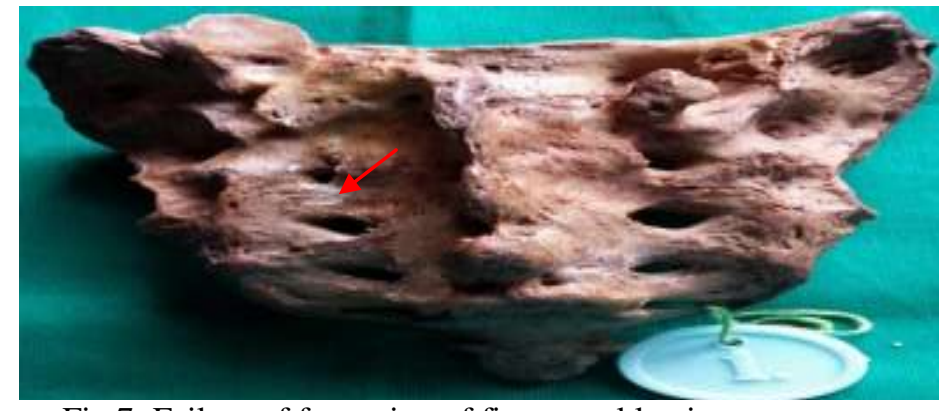

Fig.7: Failure of formation of first sacral lamina

2. Nonfusion of first sacral lamina - seen in four Sacrum.( Fig.8,9,10 \&11)

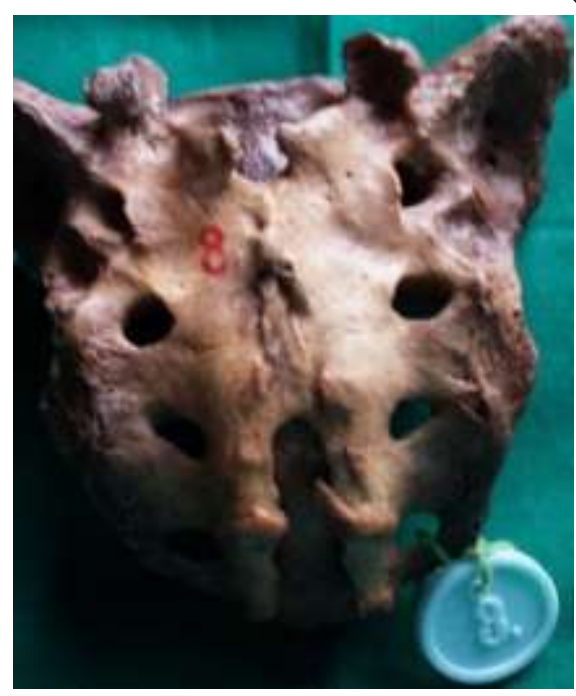

Fig.8

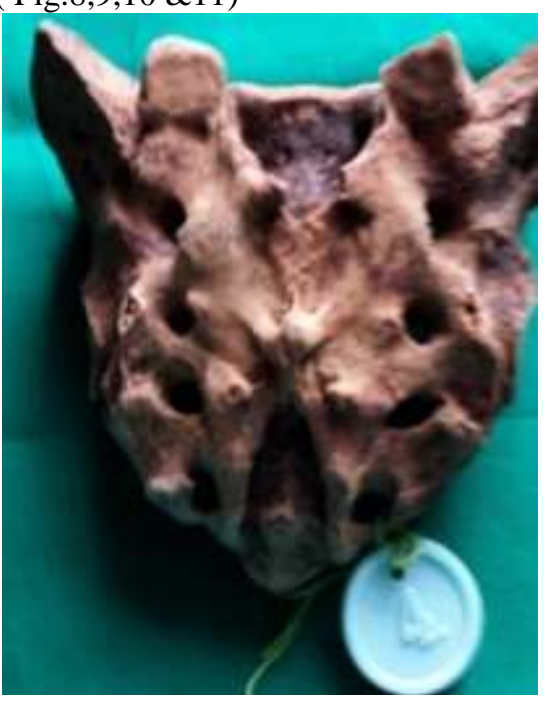

Fig.9 


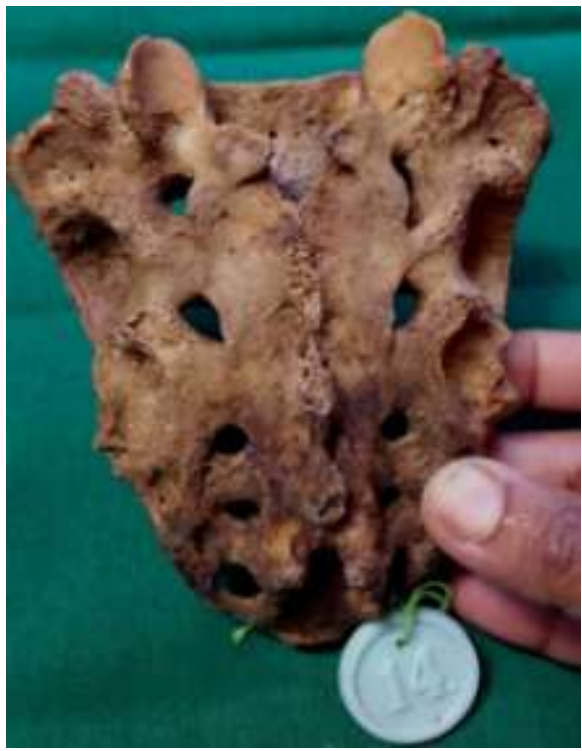

Fig.10

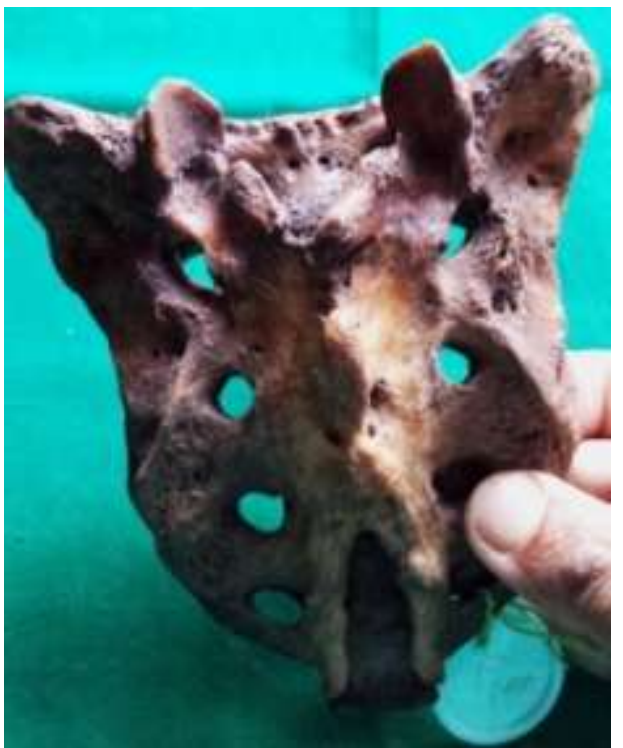

Fig.11

3. Incomplete development and nonfusion of laminas of second sacral vertebrae - seen in six Sacrum. (Fig.12,13,14,15,16 \&17)

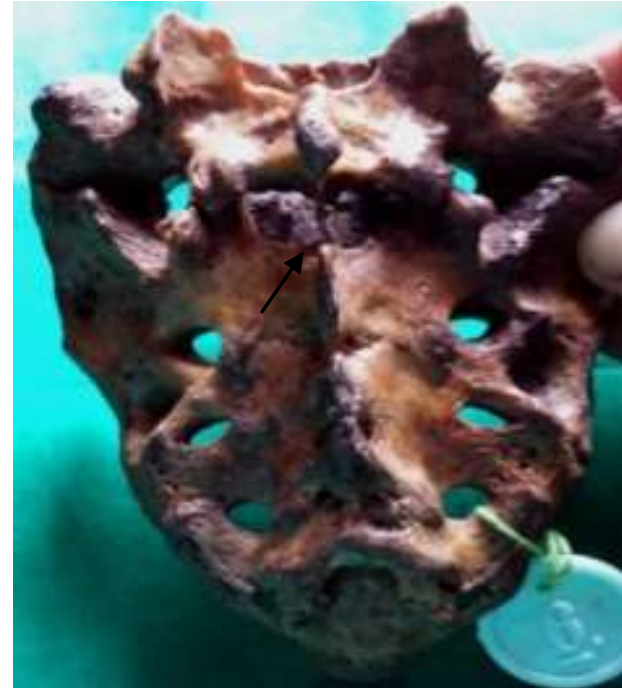

Fig.12

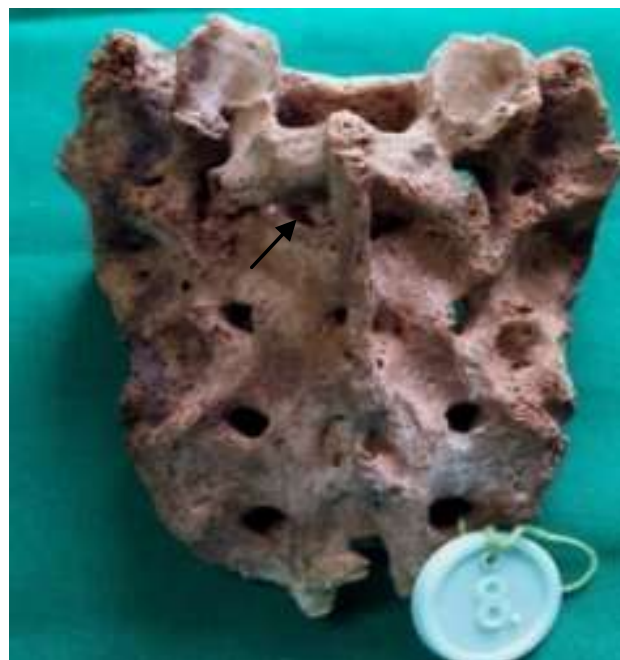

Fig.14

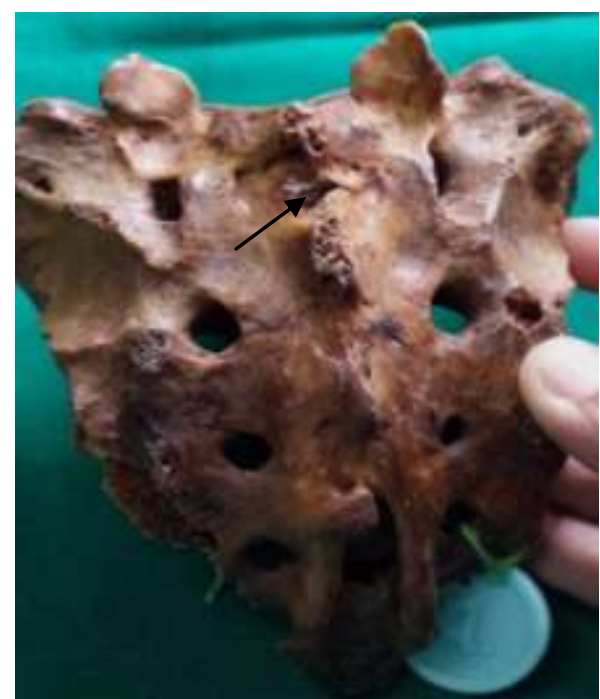

Fig.13

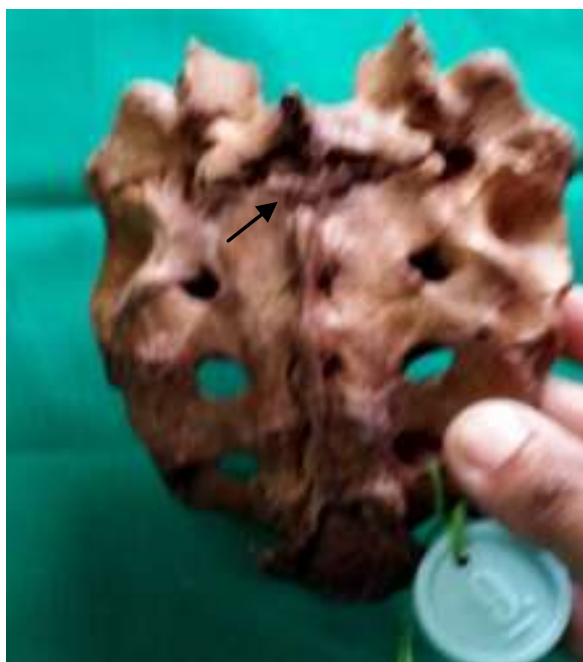

Fig.15 


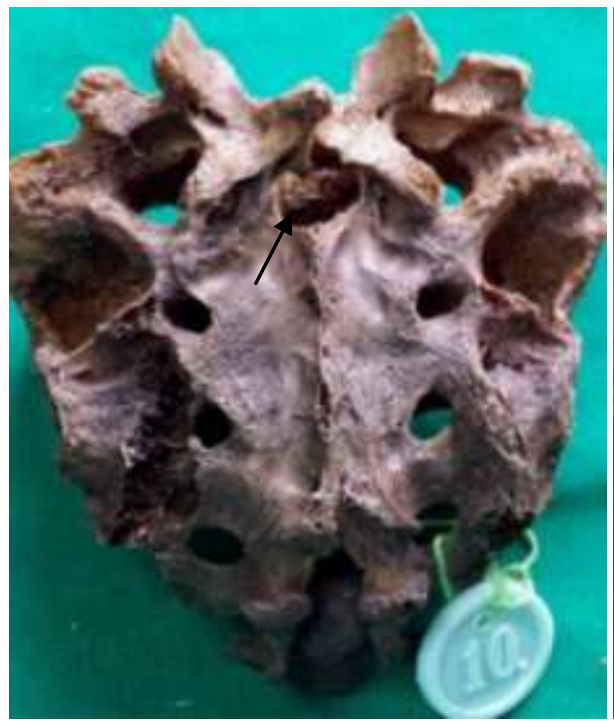

Fig.16

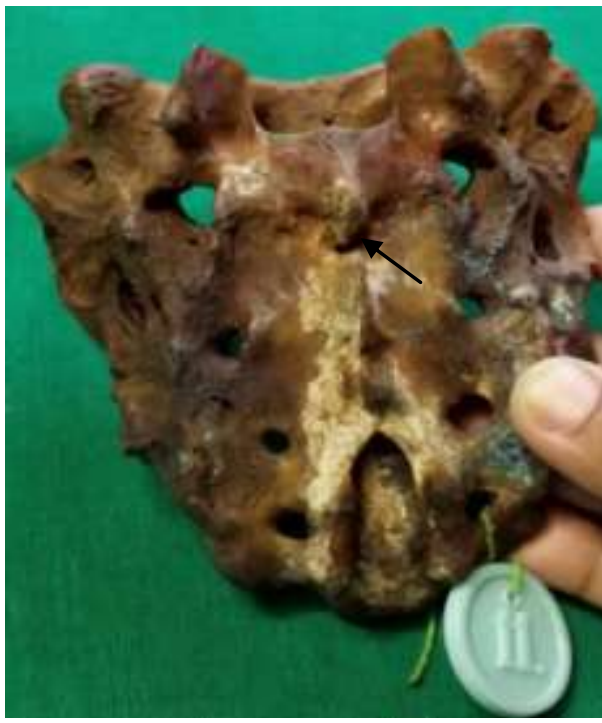

Fig.17

4. Absence of median crest with nonfusion of laminas of first and second sacral vertebrae.(Fig.18)

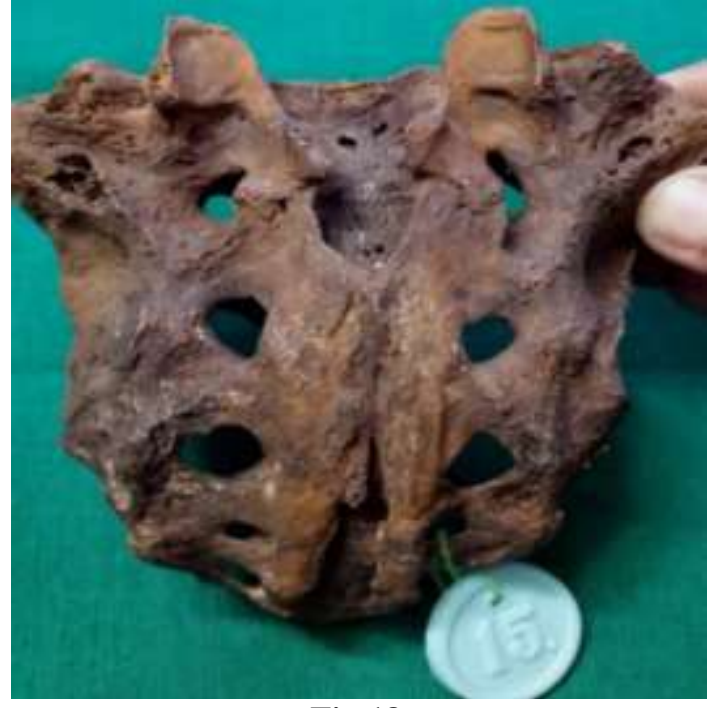

Fig.18

6. Incomplete median crest. (Fig. 19,20,21 ,22 \& 23)

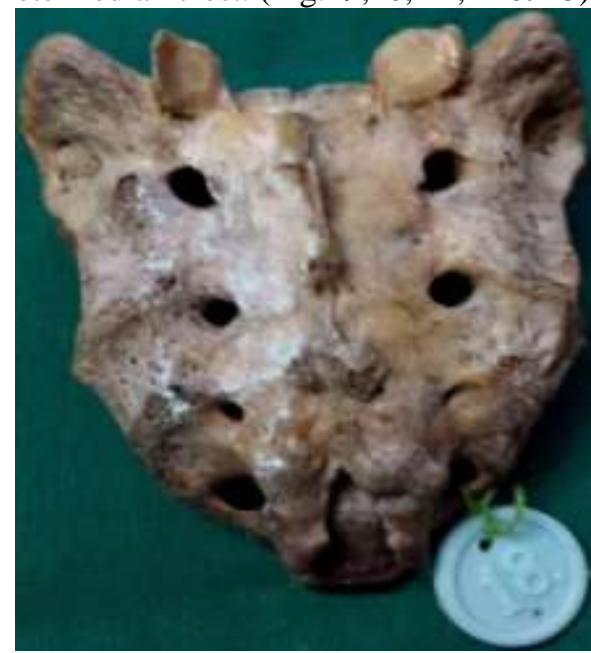

Fig.19

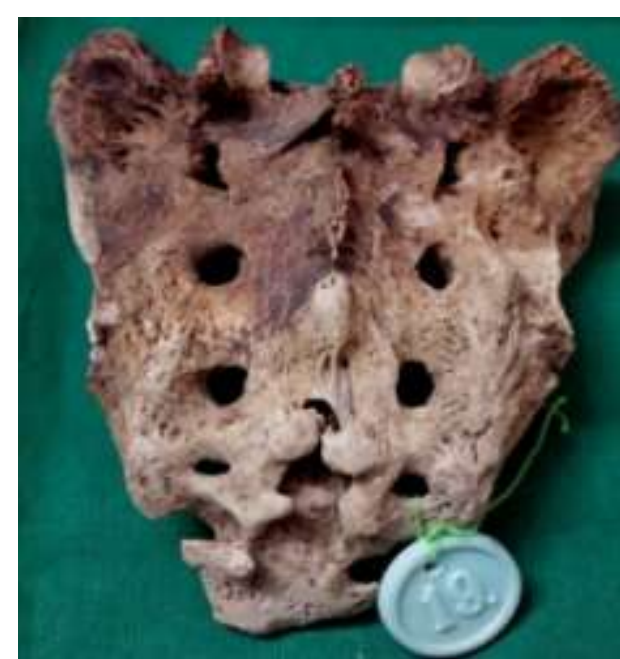

Fig.20 


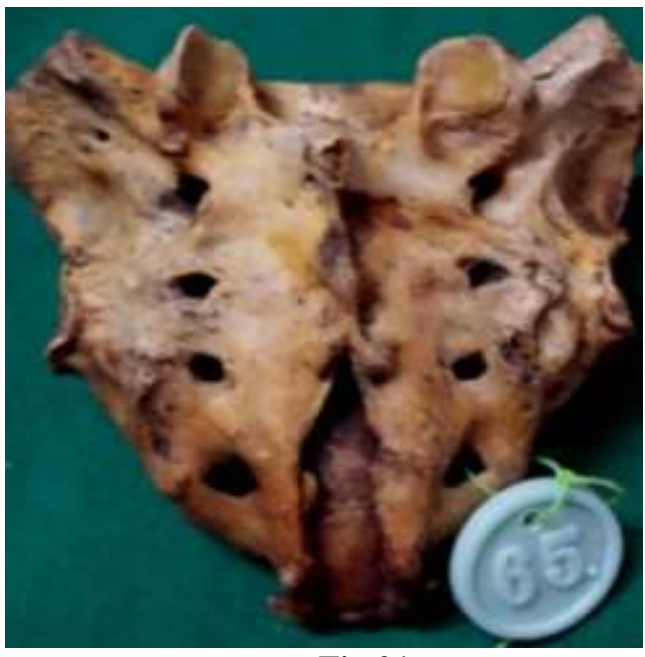

Fig.21

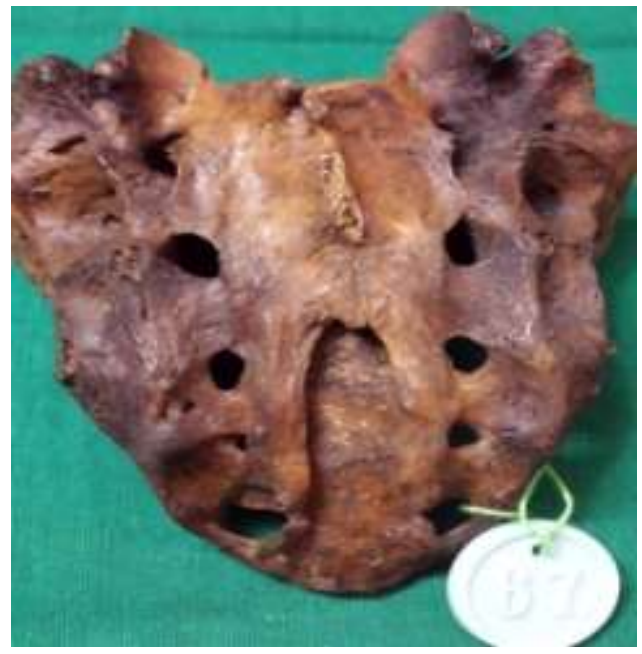

Fig.22

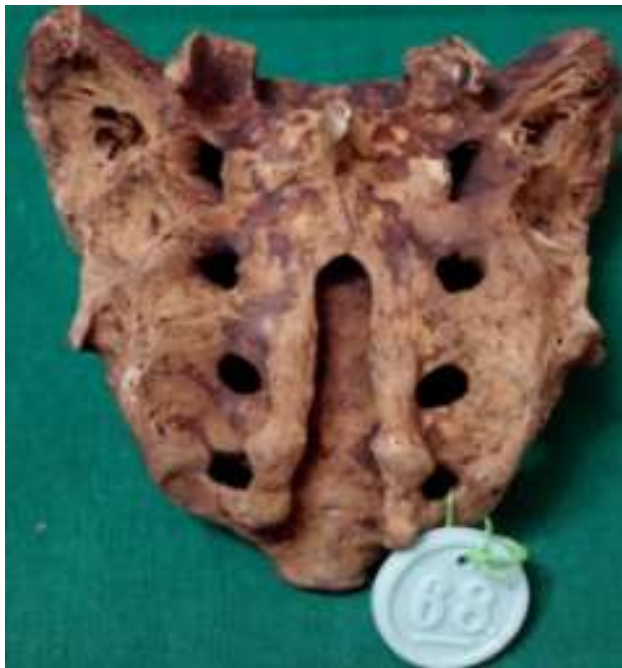

Fig.23

7. A foramina in the right side of lamina of second sacral vertebrae which indicates incomplete development of right side of second sacral vertebrae.(Fig.24 \& 25)

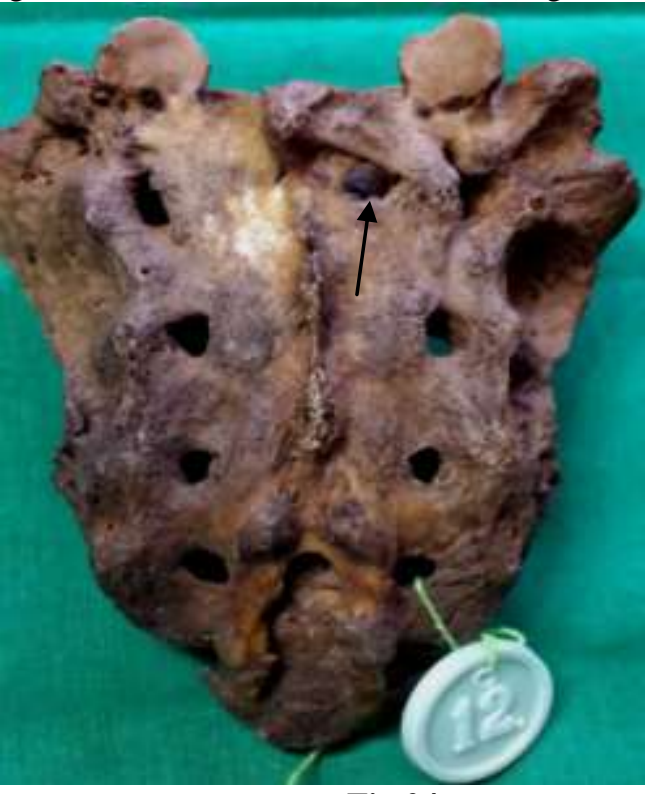

Fig.24

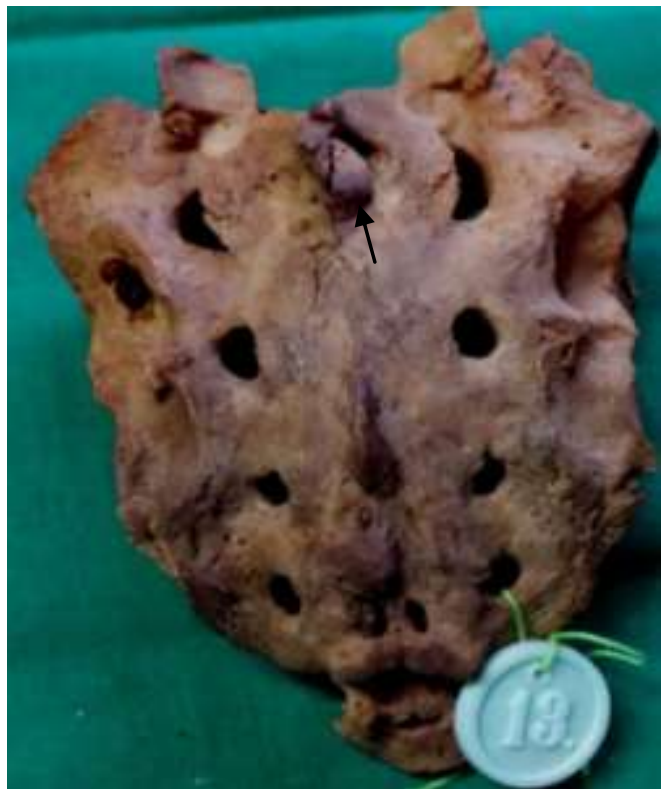

Fig.25 
7.Foramens on either side below the first spinous process and at the level of second and third spinous process with absence of median crest.(Fig.26 \&27)

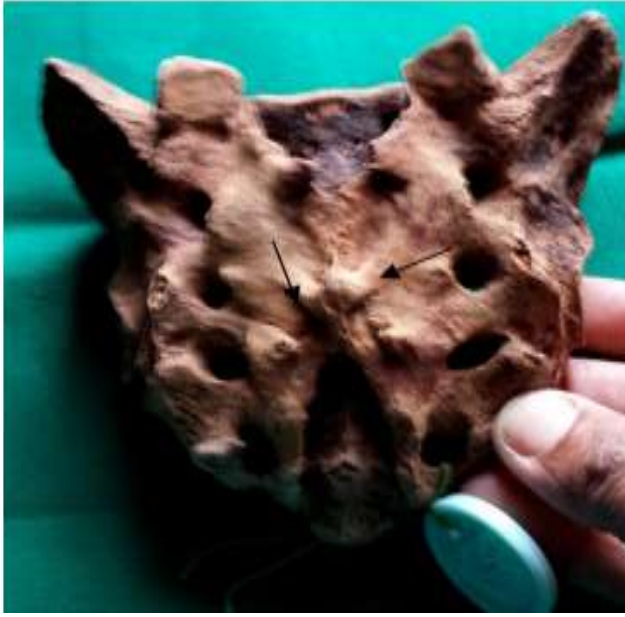

Fig.26

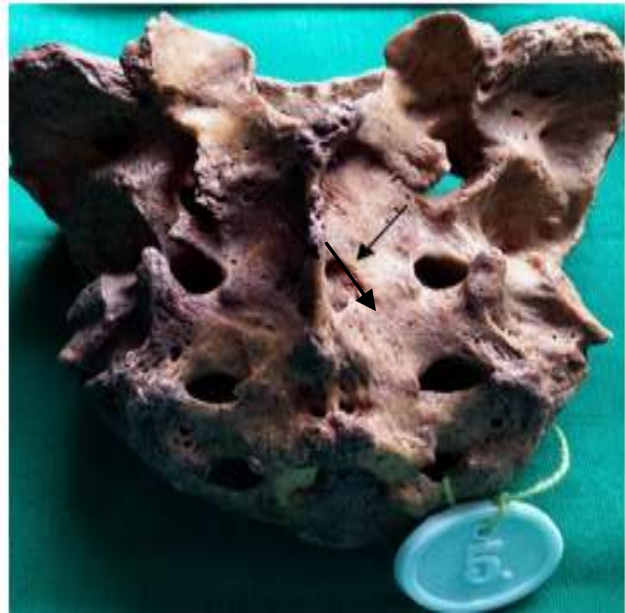

Fig.27

8. Foramen just above the apex of sacral hiatus on either side.(Fig.28.29,30 \&31)

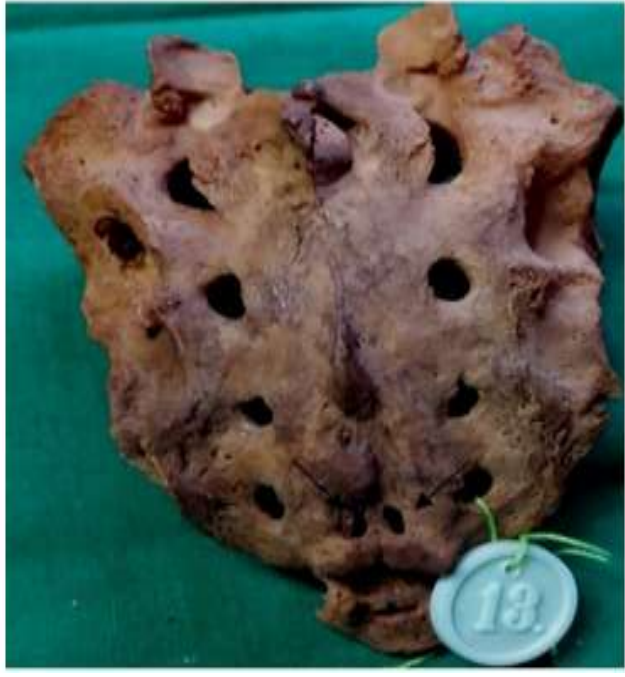

Fig.28

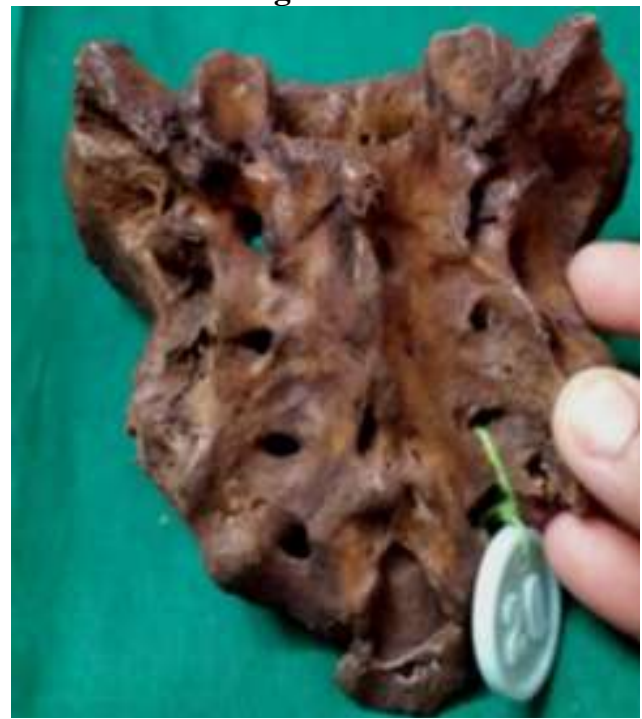

Fig.30

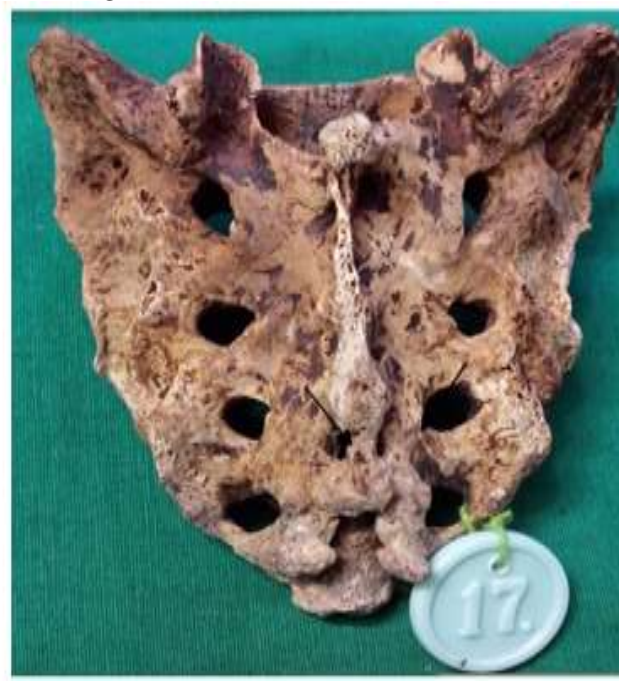

Fig.29

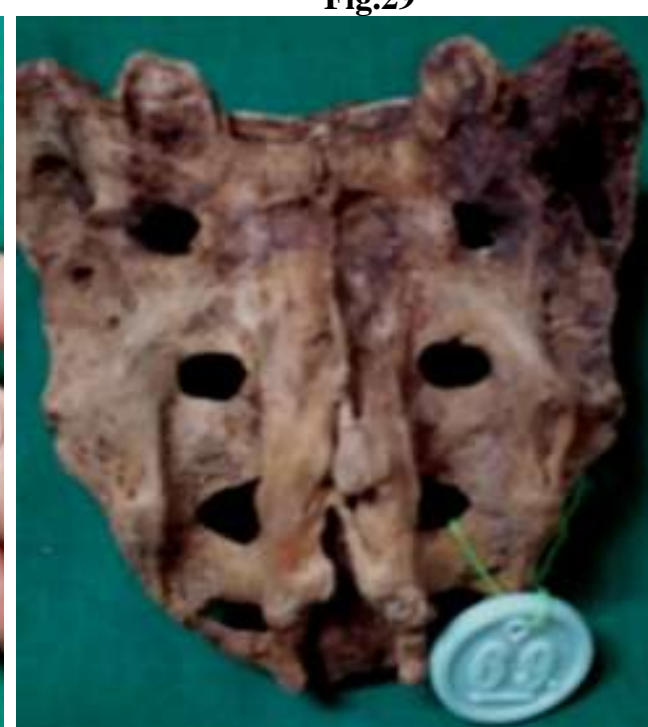

Fig.31 
9. Multiple foramen in the dorsal surface of base of sacrum behind the auricular surface in the ala for the attachment of Interosseous ligament and Dorsal sacroiliac ligament.(Fig.32)

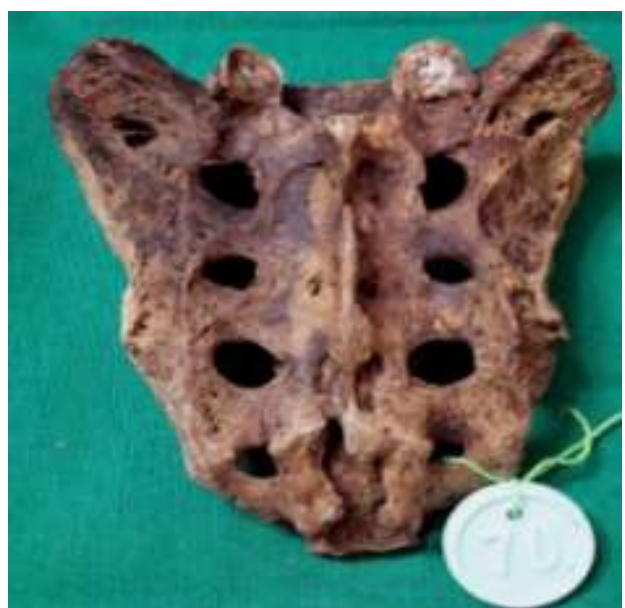

Fig.32

10. Complete dorsal wall agenesis.(Fig.33)

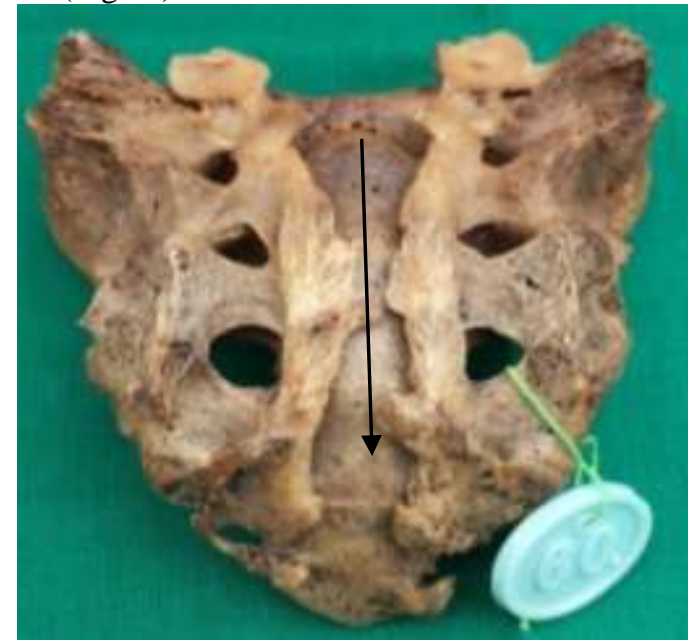

Fig.33

11. Sacralisation of fifth lumbar vertebrae.(Fig. $34,35,36 \& 37$ )

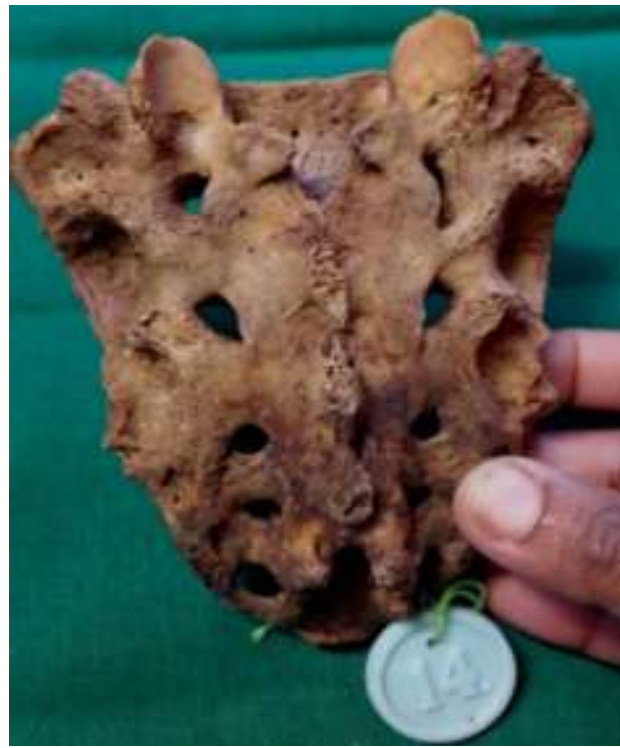

Fig.34

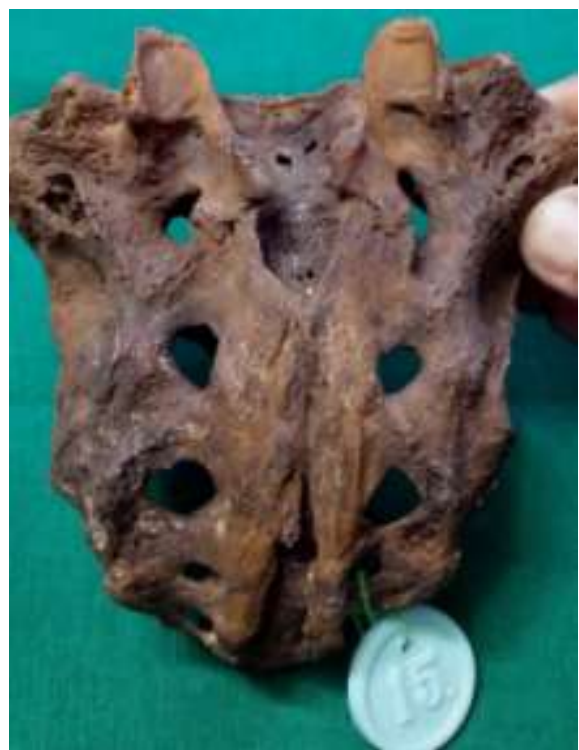

Fig.35 


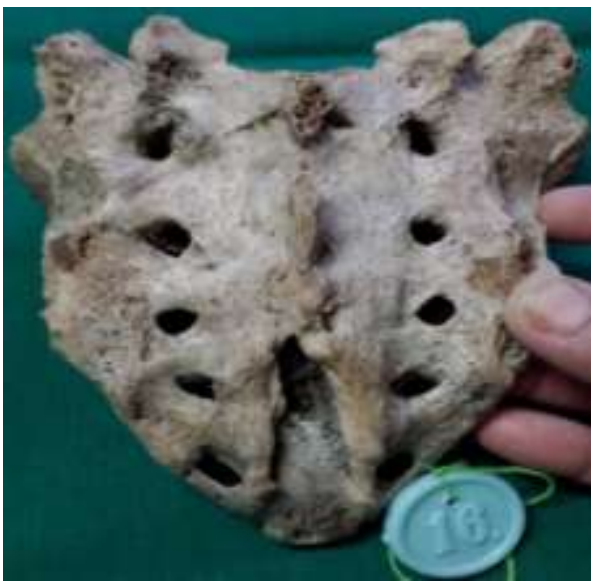

Fig.36

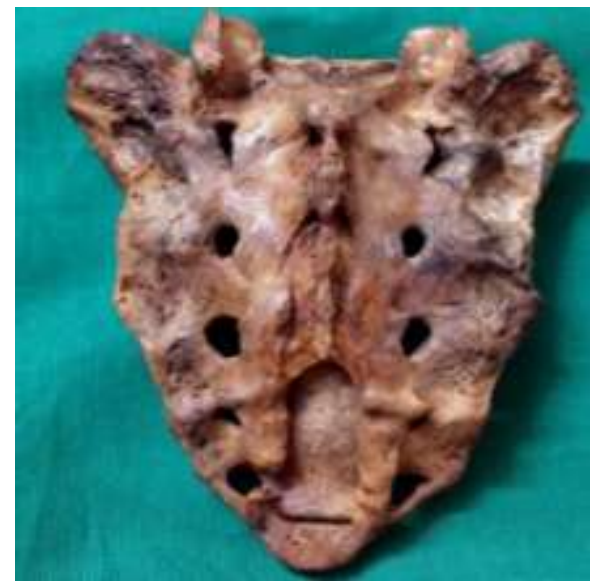

Fig.37

12. High sacral hiatus.(Fig. $38 \& 39$ )

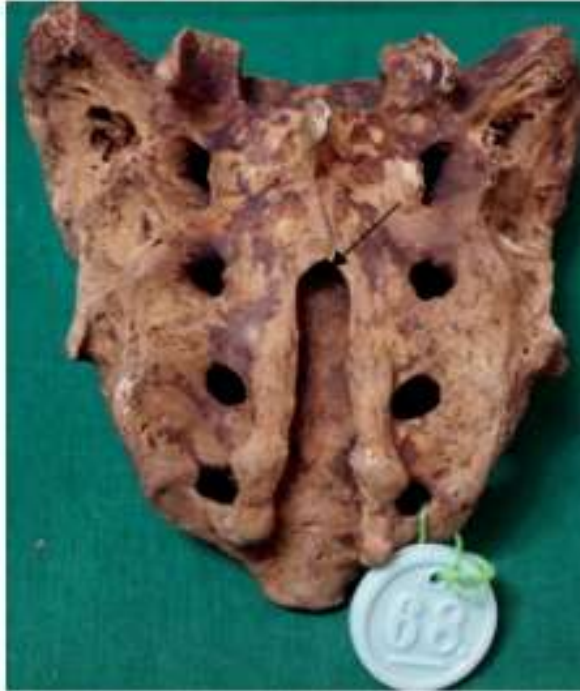

Fig.38

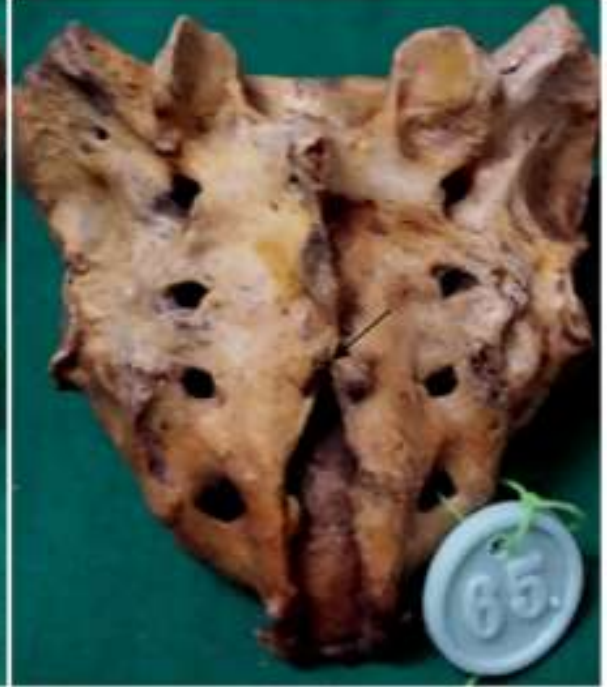

Fig.39

\section{Discussion}

Sacral composition was five segments and was about $56 \%$ which was higher. This was similar to study done by Anupriya et $\mathrm{al}^{15}$.

Shape of Sacral hiatus was inverted ' $U$ ' shaped among 27 Sacra which was higher, followed by Inverted ' $V$ 'shaped, irregular, Dumbbell, bifid in our study which was similar to study done by, Seema et $\mathrm{al}^{1}$, Nagar.S.K ${ }^{2}$, Dipali Rani Pal ${ }^{6}$ et al and Jadhav Mayuri et al.

Location of apex of Sacral hiatus was at fourth Sacral vertebrae in 36 dry Sacral vertebrae in our study.This was similar to Seema ${ }^{1}$, Nagar S.K ${ }^{2}$, Jadhav Mayuri ${ }^{8}$ studies.

Location of Base was at fifth Sacral vertebrae in 48 dry Sacra in our study which was similar to Seema et $\mathrm{al}^{1}$, Nagar S.K $\mathrm{K}^{2}$, Dipali Rani Pal ${ }^{6}$ et al studies.

Maximum curvature of Sacrum was observed to be at S3 vertebrae level which was similar to study done by A.Anupriya et $\mathrm{al}^{15}$.

Anteroposterior diameter at the sacral hiatus was about $0-3 \mathrm{~mm}$ in 35 dry Sacra in our study. In the other studies by Seema et $\mathrm{al}^{1}$, Nagar.S.K ${ }^{2}$, Dipali Rani Pal ${ }^{6}$ et al and Jadhav Mayuri et $\mathrm{al}^{8} 4-6 \mathrm{~mm}$ was observed as higher Anteroposterior diameter.

Transverse diameter was found to be $11-15 \mathrm{~mm}$ in 36 Sacra in our study. This was similar to Seema et $\mathrm{al}^{1}$, Nagar.S.K $\mathrm{K}^{2}$, Dipali Rani $\mathrm{Pal}^{6}$ et al studies.

The distance between S2 foramen and apex of Sacral hiatus was $34.6 \mathrm{~mm}$ on an average (range $6-$ $52 \mathrm{~mm}$ ) and the distance to the base of the Sacral hiatus was $51.2 \mathrm{~mm}$ (range $15-58 \mathrm{~mm}$ ) in our study. It has reported by Senoglu N et al ${ }^{16}$ that the distance between S2 foramen and apex of Sacral hiatus was $35.37 \mathrm{~mm}$ on an average (range $11-62 \mathrm{~mm}$ ) and the distance to the base of the Sacral hiatus was $65.25 \mathrm{~mm}$ (range $39-$ $85 \mathrm{~mm}$ ). It also has reported by Dipali Rani $\mathrm{Pal}^{6}$ et al that the distance between S2 and apex of Sacral hiatus was 
$31.33 \mathrm{~mm}$ on an average (range $5-60 \mathrm{~mm}$ ) and the distance to the base of Sacral hiatus was $54.88 \mathrm{~mm}$ (range 37 $-39 \mathrm{~mm})$.

Angle between the base and left side of the triangle and the angle between the base and right side of the triangle was observed to be equal which was similar to A.Anupriya et al ${ }^{15}$ study.

Complete non fusion of first sacral lamina was observed by Sushanth et al $^{9}$ study. Failure of formation of right first sacral lamina and superior articular process with abnormal bony growth near the first dorsal foramina was observed in our study.High sacral hiatus with nonfusion of lamina of first sacral vertebrae was observed by Vishal.K et al. this was also observed in our study.

Incomplete development of second sacral lamina was found in Renu Chauhan et $\mathrm{al}^{11}$ study. We found the same in six Sacral vertebra.

Rare osseous growth on the Sacrum was found on the ventral aspect of left side of first sacral vertebral body and the promontory by Puja Chauhan et $\mathrm{al}^{12}$. But in our study, We observed abnormal bony mass near the right side of first sacral foramina with failure of formation of first and second sacral lamina with superior articular process.

Complete dorsal wall agenesis of Sacrum was observed by Vanitha et $\mathrm{al}^{13}$. In our study, We observed Complete dorsal wall agenesis in one sacral vertebrae.Sacralisation of fifth lumbar vertebra was observed by Kubavat Dharati et $\mathrm{al}^{14}$. This was also observed in our study in four sacral vertebra. The development of Sacrum resembles the ossification of a typical vertebrae. The Sacrum develops from fusion of five vertebrae. After puberty, the sacral vertebrae start fusing with each other ${ }^{6}$. The primary centres which form each half of vertebral arch fuse posteriorly to to form complete sacral canal. Complete fusion of five vertebrae as single piece of bone was observed by 34 years of age. Any defect in formation leads to incomplete formation of Sacral canal and incomplete ossification of lamina. Spina bifida occulta or cystica can be accompanied and Neurological defects can be present in such cases ${ }^{14}$.

The median crest is formed primarily from the spinous process of the upper three to four sacral vertebrae $^{8}$. The lamina of fifth sacral and sometimes fourth sacral vertebrae do not fuse in the midline. As a result, the opening is termed Sacral hiatus. If the laminae of the higher sacral vertebrae are not fused, then there will be a high Saral hiatus. This kind of anatomical variation in the sacral hiatus ${ }^{7}$ may lead to failure of Caudal epidural analgesia, transpedicular and lateral mass screw placement failure.

The lamina on either side of median sacral crest form sacral grooves. Number of muscle attachments Multifidus, Sacrospinalis and Erector spinae muscles originate from these grooves. If the second Sacral lamina was not fused, the muscles would fail to get proper attachment on the dorsal aspect of sacrum. The deficiency in the bony posterior wall of sacral canal at the second sacral vertebrae level may predispose the meninges protrusion which result in Spina bifida occulta

Agenesis of dorsal wall is due to failure of fusion of Sacral lamina. Maternal Diabetes during pregnancy has been observed to cause Sacral agenesis.

The bony growth near the first dorsal foramina may be explained that instesd of a single primary ossification centre for the body, separate ventral and dorsal primary ossification centres appear for the centrum which later fuse into single. Base on this, the growth is a developmental anomaly because of the overgrowth of only the dorsal ossification centre overgrowth and incomplete fusion of this centre with first sacral body could In Sacralisation of fifth lumbar vertebrae, the transverse process of last lumbar vertebrae becomes larger than normal on one side or both the sides and fuses to the sacrum or ilium or both. This is observed in 3.6 to $18 \%$ of people and is usually bilateral. In Sacralisation usually L5 - S1 intervertebral disc becomes thin and narrow, this abnormality is found by X - Ray. The occurrence of Lumbosacral transitional vertebra (LSTV) - Lumborisation or Sacralisation of fifth lumbar vertebra is linked to its embryological development and osteological defects. Embryologically, the vertebrae receives contribution from caudal half of one sclerotome and from the cranial half of succeeding sclerotome. Because of reduction of length of vertebral column, the incidence of Sacralisation is higher than Lumborisation ${ }^{11}$.

Due to Sacralisation of fifth lumbar vertebra, the fusion of Lumbosacral joint might cause great difficulty during labour because of less mobile pelvis and may be the cause for low back pain. It is the one of the cause for lumbar disc prolapse ${ }^{11}$.

\section{Conclusion}

Clinicians need to be aware of such conditions and their frequencies because the success of Caudal epidural anaesthesia and analgesia depends on the anatomical variations of Sacrum and the hiatus. Neurological symptoms may be caused due to such anomalies. The variations of sacrum need to be known to the Anaesthetists, Radiologists, Surgeons, Orthopedicians and Gynaecologists since sacral hiatus is the site where caudal analgesia and epidural anaesthesia has been given. 
Knowledge of this type of variation may be helpful to the Radiologists in interpreting the radiographs of Sacral spine.This variation may also benefit Orthopedicians in diagnosing the cause of Lowbackpain. It is useful in diagnosing the cause of neurological involvement of bladder, rectum and lower limbs ${ }^{8}$.

The sacrum has anatomical variations and these variations are important for Caudal epidural anaesthesia. In the present study, many variations of Sacrum like incomplete formation of first Sacral lamina and superior articular process with bony growth near the first dorsal foramina, nonfusion of first sacral lamina with bony growth near the first dorsal foramina, nonfusion of second sacral lamina, absence of median crest with nonfusion of lamina of first and second sacral lamina, complete dorsal wall agenesis, Sacralisation of fifth lumbar vertebrae, elongated hiatus and narrowing of Sacral canal at the apex of the hiatus were found in higher percentage $^{1 \& 5}$. These variations should be kept in mind while giving Caudal anaesthesia.

Exact localization of Sacral hiatus would help in easy passage of needle into the sacral canal. Variations in the shape and level of the hiatus may lead to failure of Caudal epidural anaesthesia. This study will be helpful to the Anaesthesiologists in identifying the variations of Sacrum and to locate the sacral hiatus during Caudal epidural anaesthesia.

\section{References}

[1]. Seema,Singh,Mahajan. An anatomical study of variations of sacral hiatusin sacra of North Indian origin and its clinical significance.Int.J.Morphol 2013:31(1);110 - 14

[2]. Nagar S.K. A study of sacral hiatus in dry human sacra. J.Anat.Soc.India2004;53(2)18 - 21

[3]. Standring S. The Back.In: Gray’s Anatomy’s Sacrum.40 ${ }^{\text {th }}$ ed.Edinburg,UK: Churchill Livingstone $2008: 724$

[4]. Neeta V.Kulkarni. Bones of Abdomen and Pelvis.In:Clinical Anatomy, ${ }^{\text {nd }}$ edition,Jaypee Brothers.Medical publishers(P)Ltd.2012.632

[5]. Janusz piontek. Variation of level of closure of the sacral canal in man. Folia morphologica,1971,459 -64

[6]. Dipali Rani Pal, Md.ashfagur Rahman et al. Morphometric study of sacral hiatus: A basis for successful Caudal epidural block, Bangaladesh J.Anat.2012;10(1):5 - 10

[7]. Santanu Bhattacharya, Sudeshna Majumdar et al. A morphometric study of sacral hiatus for caudal epidural block among the population of West Bengal.I.J.Basic \& Applied Med.Research:Jun 2013:issue - 7,vol -2,p.660 - 67

[8]. Jadhav Mayuri, Ghorpadi vijay et al, Anatomical study of Sacral hiatus in Dry isolated sacra, J.Rearch in Medical \& dental Sci, vol.2,issue2, April - June 2014

[9]. Sushanth, Shishirkumar, Complete nonfusion of sacral lamina - A case study, I.J.S.R 2014,vol.3,issue7, 737 - 38

[10]. Vishal K, Vinay K.V, High sacral hiatus with Nonfusion of lamina of first sacral vertebrae: A case report, Nitte university, J.Health Sci,Dec 2012,vol.2, No.4, $60-62$

[11]. Renu chauhan, Jugesh Khanna, incomplete development of second sacral lamina: a case report, I.J.Research in Med.Sci,2013,vol.1,issue3,278 -80

[12]. Puja Chauhan, Sumita Kalra, Arare osseous growth on sacrum, I.J.A.V,2010;3:218 - 19

[13]. Vanitha, Taqdees Fatima, H.S.Kadlimatti, Complete dorsal wall agesis of sacrum: A case report, I.J.Dental \&Medical Sciences, 2014, vol.13,issue 4,pp80-81

[14]. Kubavat Dharati, Nagar et al, A study of Sacralisation of fifth lumbar vertebra in Gujarat, N.J.Medical Research,2012,vol.2,issue2,211 - 13.

[15]. A.Anupriya, M.Mahima Sophia, Anatomical study of Sacral hiatus in South Indian population and its clinical significance in Caudal epidural anaesthesia, N.J.C.Anatomy, July 2014, vol.3,issue3,pp128 - 36.

[16]. Senoglu N, SenogluM, Oksuz H et al, Landmarks of the sacral hiatus for Caudal epidural block: an anatomical study. Br.Janaes, 2005; 95(5):692 - 95

[17]. A.K.Datta, Essentials of Human Embryology, $6^{\text {th }}$ ed.2010; 97,278 - 79 . 